\title{
Structure, Folding and Stability of Nucleoside Diphosphate Kinases
}

\author{
Florian Georgescauld ${ }^{1, *} \mathbb{C}$, Yuyu Song ${ }^{2}$ and Alain Dautant ${ }^{3, *(\mathbb{D}}$ \\ 1 Department of Chemistry and Chemical Biology, Northeastern University, Boston, MA 02115, USA \\ 2 Department of Neurology, Massachusetts General Hospital and Harvard Medical School, Charlestown, \\ MA 02129, USA; ysong13@mgh.harvard.edu \\ 3 Institut de Biochimie et Génétique Cellulaires, Univ. Bordeaux, CNRS, IBGC, UMR 5095, \\ F-33000 Bordeaux, France \\ * Correspondence: f.georgescauld@northeastern.edu (F.G.); a.dautant@ibgc.cnrs.fr (A.D.)
}

Received: 31 July 2020; Accepted: 13 September 2020; Published: 16 September 2020

\begin{abstract}
Nucleoside diphosphate kinases (NDPK) are oligomeric proteins involved in the synthesis of nucleoside triphosphates. Their tridimensional structure has been solved by X-ray crystallography and shows that individual subunits present a conserved ferredoxin fold of about 140 residues in prokaryotes, archaea, eukaryotes and viruses. Monomers are functionally independent from each other inside NDPK complexes and the nucleoside kinase catalytic mechanism involves transient phosphorylation of the conserved catalytic histidine. To be active, monomers must assemble into conserved head to tail dimers, which further assemble into hexamers or tetramers. The interfaces between these oligomeric states are very different but, surprisingly, the assembly structure barely affects the catalytic efficiency of the enzyme. While it has been shown that assembly into hexamers induces full formation of the catalytic site and stabilizes the complex, it is unclear why assembly into tetramers is required for function. Several additional activities have been revealed for NDPK, especially in metastasis spreading, cytoskeleton dynamics, DNA binding and membrane remodeling. However, we still lack the high resolution structural data of NDPK in complex with different partners, which is necessary for deciphering the mechanism of these diverse functions. In this review we discuss advances in the structure, folding and stability of NDPKs.
\end{abstract}

Keywords: nucleoside diphosphate kinase structure; oligomeric state; quaternary structure; protein folding; protein stability; histidine kinase

\section{Introduction}

Nucleoside diphosphate kinases (NDPKs) are multifunctional oligomeric proteins [1] encoded in humans by the nucleotide metabolism enzyme (NME) genes, also called NM23 [2,3]. They are present in all three domains of life (bacteria, archaea and eukaryotes) and in some viruses. Most bacteria have only one cytosolic isoform, while eukaryotes can present up to 10 different isoforms [2,3], located in the cytosol, nucleus or mitochondria [1,4]. NDPKs are enzymes responsible for the transfer of the $\gamma$-phosphate between nucleoside triphosphates and nucleoside diphosphates via a ping-pong mechanism involving a phospho-histidine intermediate of high energy [5,6]. Inside cells, the donor of phosphate is mainly the ATP, the acceptor often being the GDP. NDPKs thus produce GTP for elongation in protein synthesis, signal transduction and microtubule polymerization; CTP for the synthesis of lipids; UTP for the synthesis of polysaccharides and NTPs or dNTPs for the synthesis of nucleic acids. In addition to these well-established metabolic functions [7-10], other important roles have been identified: some isoforms can bind DNA [11,12], act as metastasis suppressors $[1,13,14]$, 
participate in membrane remodeling through interaction with dynamins $[1,15]$ or influence cytoskeleton dynamics [16,17].

The involvement of NDPKs in different aspects of metastasis is particularly important. The interaction between NDPKs and cytoskeletal components such as actin, actin binding proteins, intermediate filaments and tubulin has been described by several groups and is thought to be highly relevant in the context of metastasis, partially due to the well-established role of cytoskeleton in cell motility and metastasis spread [16,17]. In addition, its ability to interact with other key players in cancer metastasis, such as small GTPases, G protein coupled receptors (GPCRs), ion channels, extra cellular matrix and vascular basal membrane proteins, suggests that NDPK is an important upstream regulator of multiple cancer metastasis signaling pathways $[1,18]$. Therefore, it is perhaps not surprising that NDPKs can also act as metastasis activators in certain cancer types $[13,14,19]$. In order to decipher the different roles of NDPKs and their underlying molecular mechanisms, detailed structural analyses of NDPKs need to be performed in various cellular systems in the presence or absence of specific interactors.

The first X-ray crystal structure of NDPK was solved for the hexamer enzyme from the amoeba Dictyostelium discoideum (D. discoideum) (1ndk) [20]. One year later, a second type of structural assembly was described (type I tetramer) with deposition of the structure from the bacterium Myxococcus xanthus (M. xanthus) (2nck) [21]. It took 14 more years before a third type of assembly (type II tetramer) was documented by solving the structure of NDPK from the bacterium Escherichia coli (E. coli) (2hur) [22]. Finally, a crystal structure for stable dimers was solved in 2012, constituting the fourth different type of quaternary structure for members of the NDPK family [23]. So far, 162 structures from 30 different species have been deposited within the Protein Data Bank (PDB) which fall into one of these four classes. Importantly, for all of them the monomers present a ferredoxin fold (also known as $\alpha \beta$ sandwich), in the presence or absence of ligands. The vast majority of deposited structures are hexamers, twelve belong to tetramer type I, one belongs to tetramer type II and two are isolated dimers [23-25] (Table 1). The structure of most tetramers was recently solved by a structural genomics approach yet to be published (Table 1). Today, high resolution structures are available for each type of assembly: hexamer $1.25 \AA$ (4c6a, D. discoideum) [26], tetramer type I $1.37 \AA$ (3ztp, Aquifex aeolicus) [27], tetramer type II $1.62 \AA$ (2hur, E. coli) [22] and dimer $2.30 \AA$ (3vgs, Halomonas sp. 593) [23]. NDPK crystallizes in a wide range of crystallization conditions, with a $\mathrm{pH}$ range from $4.5(1 \mathrm{wkl} / 4 \mathrm{kpc})$ to 9 (3ztq), in complex with nucleotides or analogs and dinucleotides. Ligands and buffer molecules are incorporated into the active site from the crystallization solution $\left(\mathrm{Mg}^{2+}, \mathrm{SO}_{4}{ }^{2-}, \mathrm{PO}_{4}{ }^{3-}\right.$, citric acid) [28]. In NDPK crystal forms, the volume occupied by the solvent (calculated using the CCP4 program Matthews_coef [29]) varies from $31 \%$ in hexamers (1hiy) to $75 \%$ in tetramers (3vgs). Recently, the structure of a complex formed by NDPK bound to ciliary doublet microtubules was determined by cryo-electron microscopy (cryo-EM) (6u42) [30]. The availability of these different solved structures provides a wealth of information. In this review we will focus on the NDPK structure in the view of the monomer, and its different types of physiological assemblies: dimers, tetramers and hexamers. We will discuss how monomers acquire their native conformation during the folding phenomenon and how they assemble into active complexes. Finally, the contribution of quaternary structure to the stability of NDPK will be reviewed, as well as the contribution of structural biology toward understanding the different NDPK functions. 
Table 1. Dimer and tetramer NDPK structures recently deposited in the Protein Data Bank.

\begin{tabular}{|c|c|c|c|}
\hline Id & Species (Resolution, Å) & $4 \mathrm{D}$ & Authors or References \\
\hline \multicolumn{4}{|c|}{ Betaproteobacteria } \\
\hline 4dut & Burkholderia thailandensis (2.50 ̊̊) & 4-mer & [24] \\
\hline $4 \mathrm{ek} 2$ & Burkholderia thailandensis (2.00 $\mathrm{A})$ & 4-mer & {$[24]$} \\
\hline $4 h r 2$ & $\begin{array}{c}\text { Burkholderia thailandensis } \\
\text { bound to ADP }(1.95 \AA)\end{array}$ & 4-mer & Clifton, M.C.; Abendroth, J.A. \\
\hline $5 v 6 d$ & $\begin{array}{c}\text { Neisseria gonorrhoeae } \\
\text { in complex with citrate }(1.85 \AA)\end{array}$ & 4-mer & $\begin{array}{l}\text { Abendroth, J.; Mayclin, S.J.; } \\
\text { Lorimer, D.D.; Edwards, T.E. }\end{array}$ \\
\hline \multicolumn{4}{|c|}{ Gammaproteobacteria } \\
\hline $4 \mathrm{~s} 0 \mathrm{~m}$ & Acinetobacter baumannii (1.92 Å) & 4-mer & $\begin{array}{l}\text { Sikarwar, J.; Shukla, P.K.; Kaur, } \\
\text { P.; Sharma, S.; Singh, T.P. }\end{array}$ \\
\hline $4 w b f$ & Acinetobacter baumannii (2.64 Å) & 4-mer & {$[25]$} \\
\hline $4 w 98$ & Acinetobacter baumannii (1.43 Å) & 4-mer & [25] \\
\hline 5 yih & Acinetobacter baumannii (1.98 Å) & 4-mer & $\begin{array}{l}\text { Bairagya, H.R.; Sikarwar, J.; } \\
\text { Iqbal, N.; Singh, P.K.; Kaur, P.; } \\
\text { Sharma, S.; Singh, T.P. }\end{array}$ \\
\hline $5 y o l$ & Acinetobacter baumannii (2.2 Å) & 4-mer & $\begin{array}{l}\text { Singh, P.K.; Sikarwar, J.; Kaur, } \\
\text { P.; Sharma, S.; Singh, T.P. }\end{array}$ \\
\hline $\begin{array}{l}3 \mathrm{vgs} \\
3 \mathrm{vgt}\end{array}$ & $\begin{array}{l}\text { Halomonas sp. } 593 \mathrm{WT} \\
(2.30 \AA \text { and } 2.70 \AA)\end{array}$ & 2-mer & {$[23]$} \\
\hline $\begin{array}{l}3 v g u \\
3 v g v\end{array}$ & $\begin{array}{l}\text { Halomonas sp. } 593 \text { E134A } \\
\text { mutant (2.30 ̊ and } 2.50 \AA)\end{array}$ & 4-mer & [23] \\
\hline 6aes & Pseudomonas aeruginosa (3.55 ̊̊) & 4-mer & $\begin{array}{l}\text { Sikarwar, J.; Singh, P.K.; } \\
\text { Sharma, S.; Singh, T.P. }\end{array}$ \\
\hline $5 \times 00$ & Vibrio cholerae (3.06 ̊) & 2-mer & $\begin{array}{l}\text { Agnihotri, P., Mishra, A.K.; } \\
\text { Pratap, J.V. }\end{array}$ \\
\hline \multicolumn{4}{|c|}{ Epsilonproteobacteria } \\
\hline 3pj9 & Campylobacter jejuni (2.10 ̊̊) & 4-mer & $\begin{array}{l}\text { Filippova, E.V.; Wawrzak, Z.; } \\
\text { Onopriyenko, O.; Edwards, A.; } \\
\text { Savchenko, A.; Anderson, W.F. }\end{array}$ \\
\hline 6ay1 & Helicobacter pylori (2.05 ̊̊) & 4-mer & $\begin{array}{l}\text { Edwards, T.E.; Dranow, D.M.; } \\
\text { Lorimer, D.D. }\end{array}$ \\
\hline
\end{tabular}

\section{NDPK Monomer Structure}

\subsection{The $\alpha / \beta$ Domain}

For all NDPKs, the polypeptide chain forming the base subunit adopts a similar fold regardless of the organism considered or of the presence or absence of ligands. Each subunit is made up of approximately 140 amino acids (Figure 1), with variations for the 5 amino acids at the N-terminus and the 10 to 15 amino acids at the C-terminus.

The core of the NDPK subunit forms an $\alpha / \beta$ domain of approximately 90 residues, comprising a central $\beta$-sheet of 4 antiparallel strands $\left(\beta_{2} \beta_{3} \beta_{1} \beta_{4}\right.$ topology) surrounded on each side by $\alpha$-helices (Figure 2A). The short $\alpha_{0}$ helix between the $\beta_{1}$ strand and the $\alpha_{1}$ helix constitutes the bottom of the active site pocket. 

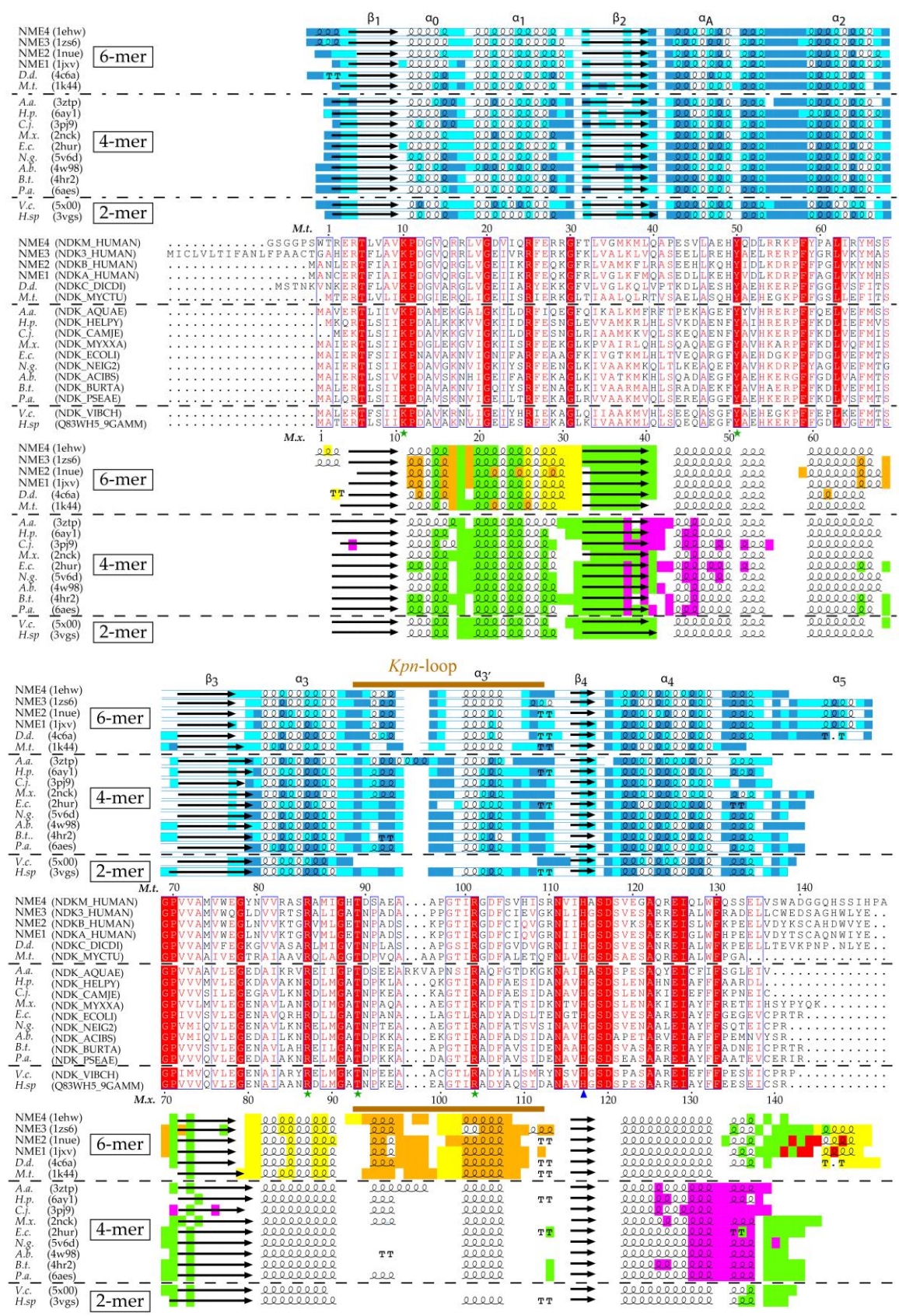

Figure 1. Secondary structure, residue accessibility, sequence and interface alignments of hexamer, tetramer and dimer NDPKs (nucleoside diphosphate kinases) with known 3D structure. (i) The relative accessibility and the secondary structure of each residue were calculated using DSSP (Database of Secondary Structure of Proteins) [31]. The accessibility is rendered as colored boxes (marine, cyan and white for accessible, intermediate and buried, respectively). $\alpha$-helices, $\beta$-strands and strict $\beta$-turns are displayed as squiggles, arrows and TT letters, respectively. The conventional names of the NDPK secondary structure elements and the Kpn-loop are indicated above. (ii) On sequence alignment, strictly conserved residues are in white on a red background while similar residues are in red on a white background with blue frames (with numbered residues of M.t. and M.x. marked above and below the alignment, respectively). The active site residues and the catalytic histidine are indicated by a green star, and a blue arrow, respectively. (iii) The various interfaces are highlighted in different colors: green for the common-dimer interface, maroon and yellow for the trimer interfaces, red for the $\mathrm{C}_{\text {Term }}$ trimer interface, magenta for tetramer interface. The interfaces were identified using PISA (Proteins, Interfaces, Structures and Assemblies) [32]. The figure was drawn with ESPript3 [33]. (NME 1 to 4, Non Metastatic human isoforms 1 to 4, D.d., D. discoideum; M.t., M. tuberculosis; A.a., A. aeolicus; H.p., H. pylori; C.j., C. jejuni; M.x., M. xanthus; E.c., E. coli; N.g., N. gonorrhoeae; A.b., A. baumannii; B.t., B. thailandensis; P.a., P. aeruginosa; V.c., V. cholerae; H. sp, Halomonas sp. 593). The PDB and Uniprot Ids are in parentheses. 


\subsection{Structural Specificities of NDPK}

The structure of the NDPK subunit has two additional characteristics: the "Kpn-loop" and the C-terminal residues extending after the $\alpha_{4}$ helix, which complete the fold [6]. The "Kpn-loop" is located between the $\alpha_{3}$ helix and the $\beta_{4}$ strand (Figures 2A and 3A). In D. discoideum, it is made up of residues $96-120$ and comprises several types of helical structural elements with an $\alpha$-helix ( $\alpha_{3^{\prime}}$ which extends the $\alpha_{3}$ helix and one turn of $3_{10}$-helix. The Kpn-loop takes its name from the "Killer of prune mutation" on the awd gene encoding a Drosophila NDPK [6]. On its own, the Kpn mutation does not cause a particular phenotype, but becomes lethal when it is associated with a dysfunction of the plum gene which codes for a protein exhibiting phosphodiesterase activity [34,35]. This mutation corresponds to the substitution by a serine of a proline conserved in all NDPKs: Pro100 for D. discoideum, Pro97 for Drosophila, and Pro96 for human NDPK-A (NME1). This loop is positioned at the active site of NDPKs and plays a role in surface contacts leading to protein oligomerization. The destabilizing effect of mutations inside the Kpn-loop will be discussed in the following section dedicated to the NDPK's stability. The C-terminal part (that is, the residues extending after the $\alpha_{4}$ helix) is one of the most mobile and variable areas of NDPK and is involved in the dimerization and trimerization of the majority of hexamers. Its length varies from 18 residues in human isoforms to 4 residues in Mycobacterium tuberculosis (M. tuberculosis) [36,37]. In contrast, the C-terminus is shorter in tetramers (see alignment, Figure 1) and is not involved in the quaternary structure.

A

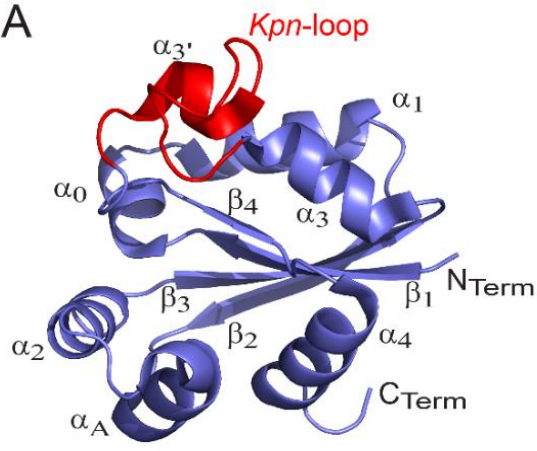

B

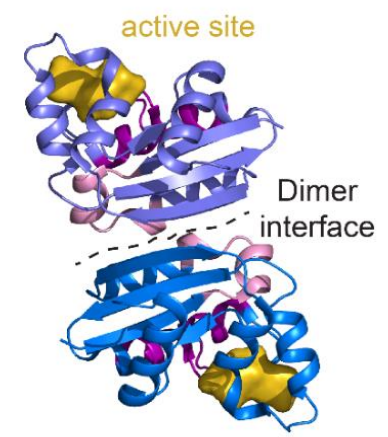

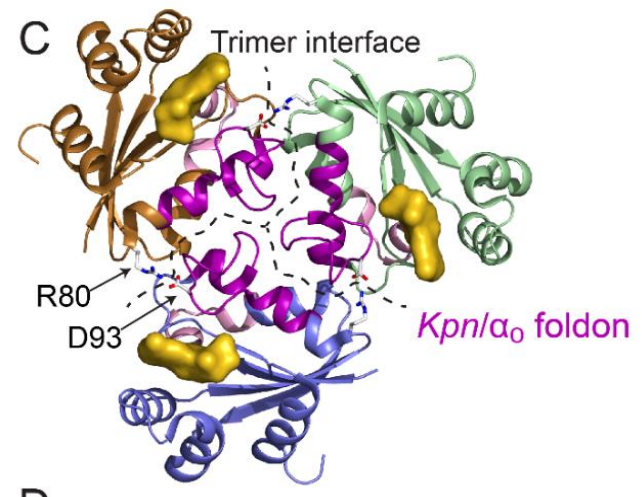

D

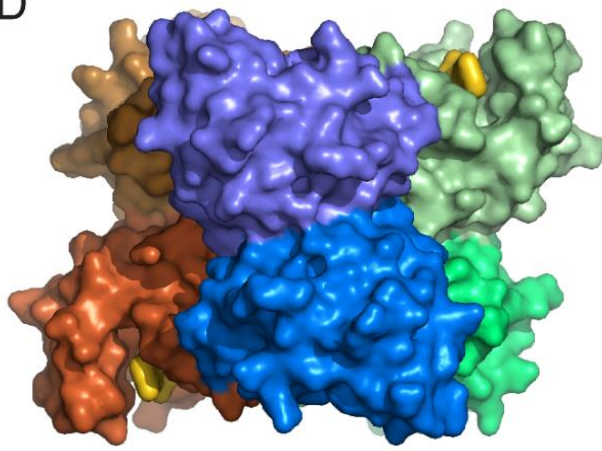

Figure 2. Structure of monomer, dimer, trimer, and hexamer of NDPK from M. tuberculosis (Figure adapted with permission from [36]). (A) View of the monomer with labeled secondary structural elements. (B) Side view of a dimer showing the dimer interface (residues 17, 19-21, 23, 24, 27, 33-38, and 72) and the active site pocket (K10, Y50, R104, N114, H117, S119, and E128). (C) Top view of a trimer. At the trimer interface (residues 16, 25, 28-31, 79, 80, 83, 84, 87, 88, 93-96, 98-102, and 105-110), the Kpn/ $\alpha_{0}$ foldon (the Kpn-loop and the $\alpha_{0}$ helix are colored magenta and pink, respectively) and the R80-D93 salt bridge (sticks) are involved in hexamer assembly. The trimer stacks in a "head-to-head" manner and not in a "head-to-tail" manner such that the $K p n / \alpha_{0}$ foldon is exposed on either side of the hexamer. (D) Side view of the surface of the six-color hexamer Mt-NDPK. The active site is colored yellow. In panels B and C, the chains are colored as in panel D. All structure figures were drawn using PyMOL molecular graphic system [38]. 


\subsection{Active Site and Substrate Fixation}

The active site comprises the nucleotide binding site plus the strictly conserved nucleophilic histidine 117 (numbered from the sequence of $M$. tuberculosis) (Figure 2A). Each monomer inside NDPK complexes presents one active site and functions independently. The catalytic histidine in the active site has been identified by direct protein sequencing, site mutagenesis and X-ray crystallography (reviewed by $[5,6,39,40]$ ).

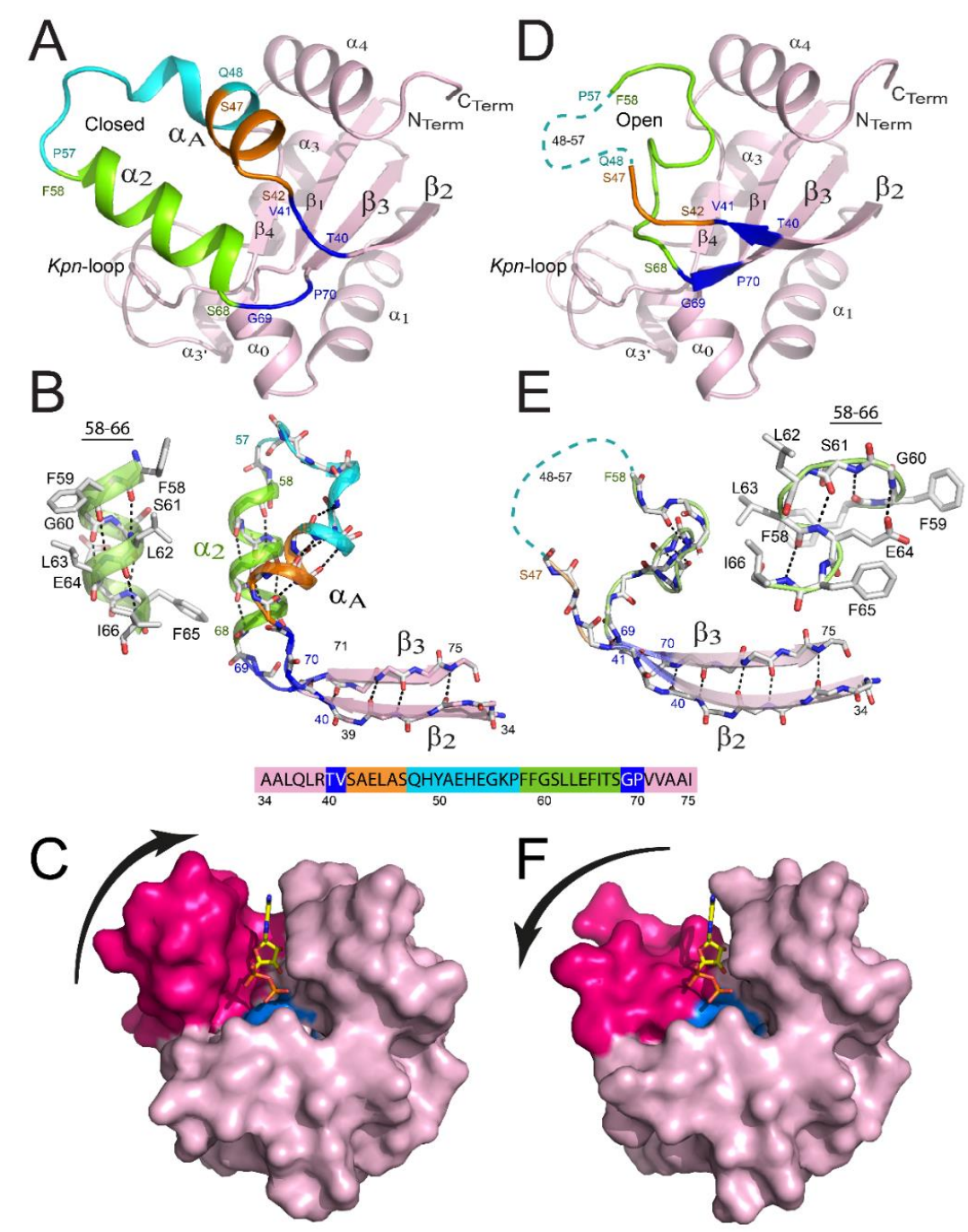

Figure 3. Remodeling of the binding site of NDPK from M. tuberculosis. View of a monomer presenting a closed structure (A) versus the remodeled one (D). The $\beta_{2} \alpha_{A} \alpha_{2} \beta_{3}$ region is remodeled in the latter monomer, and details are provided in panels (B,E), respectively. Residues 40-41, 42-47, 48-57, 58-68, and 69-70 are colored blue, orange, cyan, green, and blue, respectively. The region covering residues $48-57$ is not visible in the X-ray structure for monomers and is shown as a cyan dashed line in panels D and E. The $\alpha_{2}$ helix (B) and the successive $\beta$-turn structures (E) are shown as cartoons and ball-and-stick structures. The surface views of the monomer are displayed in the closed $(\mathbf{C})$ and open $(\mathbf{F})$ conformations. $\alpha_{\mathrm{A}}$ and $\alpha_{2}$ helices are colored magenta and the catalytic His117 is colored cyan. ADP is bound in the active site by homology with NDPK-A. (Figure adapted with permission from [41]).

Histidine 117 is located in the center of the strand $\beta_{4}$, a very short strand which follows the Kpn-loop and connects it by a "turn" forcing residue 115 (Leu or Ile in most NDPK in eukaryotes) to adopt an unfavorable conformation in order to maintain the accessibility of the substrate to the active site. Indeed, if this residue adopted a $\beta$-strand conformation, its side chain would be in contact with that 
of His117, thus blocking its access to the substrate. The accessibility of His117 is thus preserved by the formation of a hydrogen bond between the $\mathrm{NH}$ of the main chain of Leu115 and the side chain of Asp12, which is conserved in the sequences of NDPKs. His117 is also constrained by other types of interactions in order to maintain its accessibility and ensure responsive orientation. The numerous structures of NDPK resolved in the presence of different substrates show that all nucleotides bind in the same way to the catalytic site. The helical hairpin $\alpha_{A}-\alpha_{2}$ and the Kpn-loop form a kind of clamp in which the nucleotide is fixed. The base of the nucleotide is oriented towards the surface of the molecule and stacks on the conserved phenylalanine 58 , through formation of an interaction by aromatic "stacking". The phosphate part is buried and oriented towards the catalytic histidine. The interactions between the protein and the phosphate group involve the side chains of the conserved residues Lys10, Tyr50, Arg86, Thr92 and Arg104 (Figure 1). Substitution of these residues decreases the enzyme activity [42]. Finally, the ribose-phosphate moiety adopts a "folded" conformation that allows the oxygen connecting the $\beta$-phosphate and the $\gamma$-phosphate to form a hydrogen bond with the $3^{\prime}-\mathrm{OH}$ of the sugar, which is $3^{\prime}-\mathrm{OH}$ itself involved in hydrogen bonds with Lys10 and Asn114. These bonds are essential for catalytic activity, the $3^{\prime}$-deoxynucleotides being poor substrates for NDPK $[5,43]$. The divalent cation, usually magnesium, binds to $\alpha$ - and $\beta$-phosphates and is necessary for the catalytic reaction. The structure of $M$. xanthus NDPK (1nlk) resolved in the presence of ADP without $\mathrm{Mg}^{2+}$ shows that cations are not necessary for substrate binding, the phosphate part being disordered in the structure [21]. In contrast, in complexes containing $\mathrm{Mg}^{2+}$, the cation forms six bonds with the oxygens of the phosphates or with water molecules, stabilizing and keeping the phosphate group in a reactive position [6,44].

Recently, an important remodeling has been revealed for one trimer inside the NDPK hexamer from M. tuberculosis (Figure 3D-F), the second trimer presenting the classical unmodified conformation (Figure 3A-C) [41]. The remodeling was identical for all three subunits of the trimer, covering residues 40-70 and contributing to: (i) the full disappearance of $\alpha_{A}-\alpha_{2}$ helix hairpin; (ii) the appearance of a new structure formed by successive $\beta$-turns of type I and II covering residues 58-66; (iii) the increase of lengths for strands $\beta_{2}$ and $\beta_{3}$; and (iv) the absence of stable structure for the region covering residues 48-57 that are no longer visible in the electron densities. As a result, the cleft of the binding site became more open, rendering the catalytic His117 significantly more accessible to substrates. Importantly, hydrogen deuterium exchange mass spectrometry (HDX-MS) revealed that residues 40-70 are the only ones inside the hexamer that are fully solvent accessible, indicating that an equilibrium between these two conformations is possible (Figure 3C,F). Such behavior was also noticed for the WT (wild type) as well as for two point-mutants (R80A; R80N) for which the mutation site is not part of the remodeled region of the protein [41]. It is tempting to speculate that such equilibrium occurs in vivo, explaining how bulky substrates (e.g., nucleic acids or peptides) access the catalytic His117.

Twenty-six crystal structures of viral NDPK (apo and in complex with various nucleotides) have been determined at resolutions ranging from $1.5 \AA$ to $2.8 \AA$ [45]. They are all hexamers and differ from eukaryotic NDPKs by presenting shorter Kpn-loops and two viral specific residues, near the active site. These differences structurally explain their stronger affinity for both deoxynucleotides and pyrimidine nucleotides, necessary for the replication of an AT-rich viral genome in a thymidine-limited host environment.

\section{NDPK Quaternary Structure}

\subsection{Dimer: The Basic Subunit of NDPK Oligomer}

All functional NDPKs so far described in the literature are oligomers [27,37,46]. Eukaryotic NDPKs are hexamers, while prokaryotic NDPKs are hexamers or tetramers [6,46]. Regardless of the oligomerization state of these enzymes, the oligomers are always constructed from a dimer formed by two subunits assembled head to tail $[6,46]$. The dimer interface is carried out through the combination of two $\beta_{2}$ strands, one from each subunit, thus allowing the formation of a single antiparallel sheet 
of $8 \beta$-strands (Figure 2B). Comparisons between dimers from the hexamer (of $D$. discoideum) or the type I tetramer (from the deltaproteobacteria M. xanthus), and dimers from type II tetramer (from the gammaproteobacteria E. coli), show that the root mean square deviations (rmsd) for the structurally equivalent $C \alpha$ carbons were $1.4 \AA$ and $1.1 \AA$, respectively, clearly demonstrating that all NDPK oligomers share the dimer as basic structural unit. Such a NDPK dimer was found in Halomonas sp. 593 (a halophilic bacterium) using size-exclusion chromatography coupled with multi-angle laser light scattering (SEC-MALLS) [47] and the resolution of the structure confirmed its dimeric state (3vgt and 3vgs) [23]. Interestingly, the WT NDPK was able to form a type I tetramer through a single mutation E134A, situated at the tetrameric interface (3vgu and 3vgv) [23]. Recently, the second structure of a WT dimer was solved for Vibrio cholerae NDPK (5x00) (Table 1). Although the $\alpha_{3^{\prime}}$ helix and the Kpn-loop were unobserved, the best superimposition with other NDPKs resulted in a rmsd of $0.41 \AA$ for the monomer and $0.54 \AA$ for the dimer of E. coli NDPK.

\subsection{Hexamer and Tetramer of NDPK}

Functional NDPK oligomers are formed from the assembly of dimers [6,46]. The dimers self-assemble, two or three times into tetramers or hexamers [22]. One main difference between hexameric and tetrameric NDPKs comes from the C-terminal segment (Figure 1), which is longer for most hexameric NDPKs: it brings the two dimer subunits into contact and also participates in their trimerization. A C-terminal segment of 15 residues on average is responsible for an additional burial of the protein surface of about $30 \%$ (or about $300 \AA^{2}$ ) compared to the enzymes which lack such segments and which strongly stabilizes the hexamer $[37,48]$. In the NDPK from $D$. discoideum the P100S mutation combined with the successive deletion of the last 5 C-terminal amino acids leads to a loss of activity as well as the dissociation of the enzyme into dimers [48,49]. That being said, the shorter C-terminus is not sufficient to explain this difference in oligomerization and exceptions exist: the structures from M. tuberculosis [50] and from Bacillus halodenitrificans [51] are hexameric although their sequence contains a short C-terminal segment. For these short NDPKs other mechanisms exist to stabilize the hexamers as revealed by the structural analysis of destabilized mutants (see chapter on NDPK stability). For eukaryotes containing different NDPK isoforms, it has been recently reported that their hexamers are heterohexamers (containing at least two different isoforms); isoform-pure hexamers (also known as homohexamers) scarcely exist in vivo [52].

In the tetrameric structures of types I and II, the C-terminus is shorter and only interacts with the neighboring subunit inside the same dimer [46]. By assembling into hexamers or tetramers, dimers interact through different interfaces and details concerning specific residues involved in different interfaces were discussed by Moynié and colleagues [22]. In solution, the NDPK tetramers from E. coli dissociate into dimers when the concentration of the enzyme decreases [53], raising the question of the existence of an intracellular equilibrium between dimers and tetramers. It would be interesting to understand how the shift from tetramer to dimer affects the enzymatic activity, though both oligomers present strictly identical catalytic sites.

The type I tetrameric interface of the NDPK from M. xanthus is characterized by a small buried surface area (bsa: $500 \AA^{2}, 6.6 \%$ of the accessible surface area (asa) of the monomer). Surface areas have been calculated using PISA [32]. Such an interface was not present in the E. coli NDPK crystal contacts, whereas the opposite face of the dimer was buried (bsa: $470 \AA^{2}, 6.2 \%$ of the asa of the monomer), leading to the proposal of a type II tetramer. In the case of small biological interfaces, it is very difficult to distinguish the contacts which are biologically relevant from the lattice contacts. As a result, the software dedicated in crystallography to identify interfaces could fail in deciphering the real assembly. As part of structural genomic programs, several tetramer structures were recently deposited at the PDB (Table 1). These structures are type I tetramers and displayed a modest bsa about 365-490 $\AA^{2}$. Interestingly, one of them (3pj9) displays dimeric and tetrameric interfaces with similar bsa $680 \AA^{2}$ and $610 \AA^{2}$, respectively, and forms a type I like tetramer. In light of all deposited X-ray crystal structures on NDPK tetramers, determining the real biological interfaces based only on the crystal 
structure seems risky, and thus complementary approaches such as cross linking mass spectrometry or NMR are needed to reliably identify these interfaces.

\subsection{The NME Family}

Ten human genes (NME1-10) encode isoforms of NME [2,3] where the gene products differ in their functions and subcellular localizations (for a review see [54]). Structures are available for NME1 (1jxv, 1ucn, 2hvd, 2hve, 317u, 4eno, and 5ui4), NME2 which is also a transcription factor (1nsk, 1nue, $3 \mathrm{bbb}, 3 \mathrm{bbc}$, and 3bbf), NME3 involved in DNA repair (1zs6), the mitochondrial NME4 (1ehw) that interacts with cardiolipin-containing membranes [55], and FAP67 (an analog to NME7) (6ua2).

\section{NDPK Folding}

Mutants of NDPKs have provided insights into the dynamics of folding and functional diversity. For example, in addition to the well-characterized nucleoside kinase activity, the human isoform A (further called NDPK-A or Nm23-H1) is the first metastasis suppressor gene identified [56]. Although mutations are rare for this isoform, an S120G point mutation was found in several advanced neuroblastomas but not in limited-stage tumors [57], and since then, intensive research has been performed on NDPK-A (see recent review by [13]). First studies of the mutated protein showed an altered interaction with cellular partners in vivo, and its biochemical characterization showed that conversely to the WT which only form hexamers, the mutant formed hexamers as well as sub-hexameric species as monomers, dimers or tetramers [58]. In this context, the hypothetical aberrant folding and assembly of NDPK-A was studied by several groups [59-62].

Studies of recombinant S120G NDPK-A showed reduced thermal stability to denaturation, when compared to the wild type protein [61]. More interestingly, while the WT protein denatured in urea, renatured and associated into active hexamers by dilution in vitro, the S120G mutant remained as monomeric, as a molten globule folding intermediate [61]. It was also noticed that the folding defect of the S120G mutant was corrected in vitro by the presence of ATP (Ioan Lascu, personal communication during the 3rd international conference on NDPK, Bordeaux 1999) and two mechanisms through which the folding defect was corrected were discovered a few years later. The first mechanism involves phosphorylation on its catalytic histidine, which completely corrected the folding defect. It was shown that after phosphorylation by ATP or phosphoramidate, the S120G mutant renatured and assembled rapidly in high yield [62]. Binding of nucleotides (ADP, AMP-PNP) had no effect on folding, but increased the stability of native hexamers. It was proposed that protein phosphorylation was the physiological mechanism that explains why the S120G mutant is active in neuroblastomas and why it is produced as native hexamers in E. coli, despite the folding defect observed in vitro. The second mechanism involves the chemical chaperone trimethylamine-N-oxide (TMAO), which was able to correct the folding defect of the S120G mutant through its unfavorable interaction with the main chain of the protein [59]. This complements the first mechanism based on phosphorylation, as TMAO acts on both folding and assembly of monomers. The native hexameric structure of the S120G mutant did not show any difference from the WT, both for the overall structure and in the vicinity of the mutation [60]. The strong structural similarities between the two agreed with the comparable kinase activities [61] and indicated that the specificities of the S120G mutant cannot be attributed to NDPK activity. This suggests that other properties of this multifunctional enzyme may be affected by the mutation, such as the interaction with its substrates: proteins and/or DNA. Finally, it was shown in vitro that S120G hexamers lost their native conformations and formed beta amyloids [63] which might play a role in cancer. WT NDPK-A also formed amyloid aggregates when incubated at temperatures above $60^{\circ} \mathrm{C}$. However, NDPKs from other organisms were not able to form such aggregates, suggesting that the molten-globule-type folding intermediates, which are unique for human NDPK-A, may be required in the formation of amyloid structures. The presence of such amyloid structures in cancer biology has been proposed [64], suggesting that cellular factors may exist to produce molten globule intermediates in addition to high temperature incubation. 
The folding and assembly process of the NDPK from $D$. discoideum was also studied $[48,65,66]$ by classical biochemistry experiments to show that dimeric mutants of NDPK were unable to autophosphorylate, suggesting that dimers may not be able to bind the substrate. We recently confirmed this hypothesis using HDX-MS technology at the peptide level. Characterizing stable dimers from $M$. tuberculosis, we showed that they were native-like, except for a part of the binding site we called $K p n / \alpha_{0}$ subdomain which remained unfolded [36]. These dimers were unable to get phosphorylated presumably due to the fact that their binding sites are not fully constituted. Only after assembly into hexamers do the $\mathrm{Kpn} / \alpha_{0}$ subdomains get structured and the NDPK becomes enzymatically functional. That constitutes a scenario different from the one observed for tetramers, in which the $\mathrm{Kpn} / \alpha_{0}$ subdomain is folded in both dimers and tetramers. Finally, several studies used NDPK as model for understanding the effect of osmolytes on monomer folding or their assembly $[59,67,68]$ and demonstrated that folding of halophilic NDPKs required high salt concentration [67].

\section{NDPK Stability}

Studies on the differential stability for NDPKs with mutations that do not affect basal enzymatic activity and natural variants have been valuable for elucidating mechanisms for stabilization of complex structures. Initial studies were performed on the stability of NDPKs because of the discovery of defective mutants involved in tumor metastasis in cancer patients $[57,58]$ and in the aberrant larval development in Drosophila [69]. Interestingly, these mutations destabilized the structures of the monomers (e.g., the human S120G HA isoform) [59,61,62] or the hexamers' quaternary structure (e.g., the Drosophila P97S mutant) [69] without significantly affecting the enzymatic activity. Pioneering microcalorimetry studies used NDPK as a model oligomeric protein to understand the effect of quaternary structure on the complex stability [70]. More recently, additional studies used NDPK complexes as model proteins to understand how the stability of homo-tetramers or homo-hexamers is improved for extremophiles like halophiles [71-74], thermophiles [27,75] and psychrophiles [76]. Often, they used the same strategy to show through mutational analysis how different residues affect the overall stability of NDPK complexes. Other studies on NDPK stability concerned proteins from trypanosomatid parasites of subfamily Leishmania, which are secreted and must be stable enough for performing their function in potentially hostile conditions [77-80]. All these different studies stressed out the key role of the specific structures of NDPK (the Kpn loop and the C-terminal segment) in the stabilization of the quaternary structure. Finally, because NDPKs are an old family of proteins, they also provide an opportunity for studying the stability of proteins during evolution $[67,81,82]$. These studies concluded that ancient sequences of NDPK were thermally extremely stable and needed a restricted alphabet of only 13 different amino acids to be enzymatically active $[83,84]$.

Because of the limited space, we will focus only on recent articles using available structural data to explain some mechanisms through which the NDPK complexes are stabilized. Mycobacterium tuberculosis, the pathogen responsible for tuberculosis, escapes the immune system by blocking inside macrophages the maturation of phagosomes supposed to destroy it $[85,86]$. This complex mechanism requires high stability of bacillus proteins, including that of NDPK [87]. As mentioned in the section describing the NDPK structure, the majority of NDPKs present at the C-terminal a segment of 7 to 16 amino acids which interacts with two neighboring subunits and these interactions participate in the overall stability of the hexamers. In M. tuberculosis, NDPK does not have this segment, but their hexamers are thermostable and present a $\mathrm{T}_{\mathrm{m}}$ of $76{ }^{\circ} \mathrm{C}$ [50]. Combining structural biology and point mutants, we showed that their stabilization is due neither to the existence of additional hydrophobic patches, nor to hyper-stabilization of the monomers [37], but occurred through a strengthening of the ionic interactions between neighboring subunits (Figure 4A), which compensated for the absence of the stabilizing segment at the C-terminal. The stabilizing role of the six salt bridges (D93-R80) was shown by the study of the mutant D93N which loses these bonds and exhibits a $28^{\circ} \mathrm{C}$ destabilization, with a $\mathrm{T}_{\mathrm{m}}$ of $48^{\circ} \mathrm{C}$ (Figure 4B). Unexpectedly, the R80N mutant (for which the six D93-R80 salt bridges are destroyed) exhibited a stability close to that of the wild-type protein, with a Tm of $69^{\circ} \mathrm{C}$. The $1.9 \AA$ 
resolution of the R80N mutant structure provided the mechanism: the side chain of N80 forms two new strong hydrogen bonds with two neighboring subunits (Figure 4C) [28]. Another stabilizing mechanism was discovered by analyzing the structure of R80A mutant, which also shows little destabilization ( $\mathrm{T}_{\mathrm{m}}$ of $69^{\circ} \mathrm{C}$ ), despite the disappearance of ionic bonds [41]. In this case, stabilization was generated through the formation of a hydrophobic patch including the hydrophobic Ala93 (Figure 4D). Studies on tetrameric NDPK from the hyperthermophile Aquifex aeolicus showed the existence of still another stabilizing mechanism: the formation of disulfide bridges between the subunits [27]. Finally, Pédelacq and collaborators showed that hyper-stabilization for archaeal NDPK from Pyrobaculum aerophilum is realized through appearance of additional subdomains [75]. Together, these studies underscore the critical role of quaternary structure in the stability of NDPK and showed that during evolution, different stabilization mechanisms can develop inside the same family of proteins.
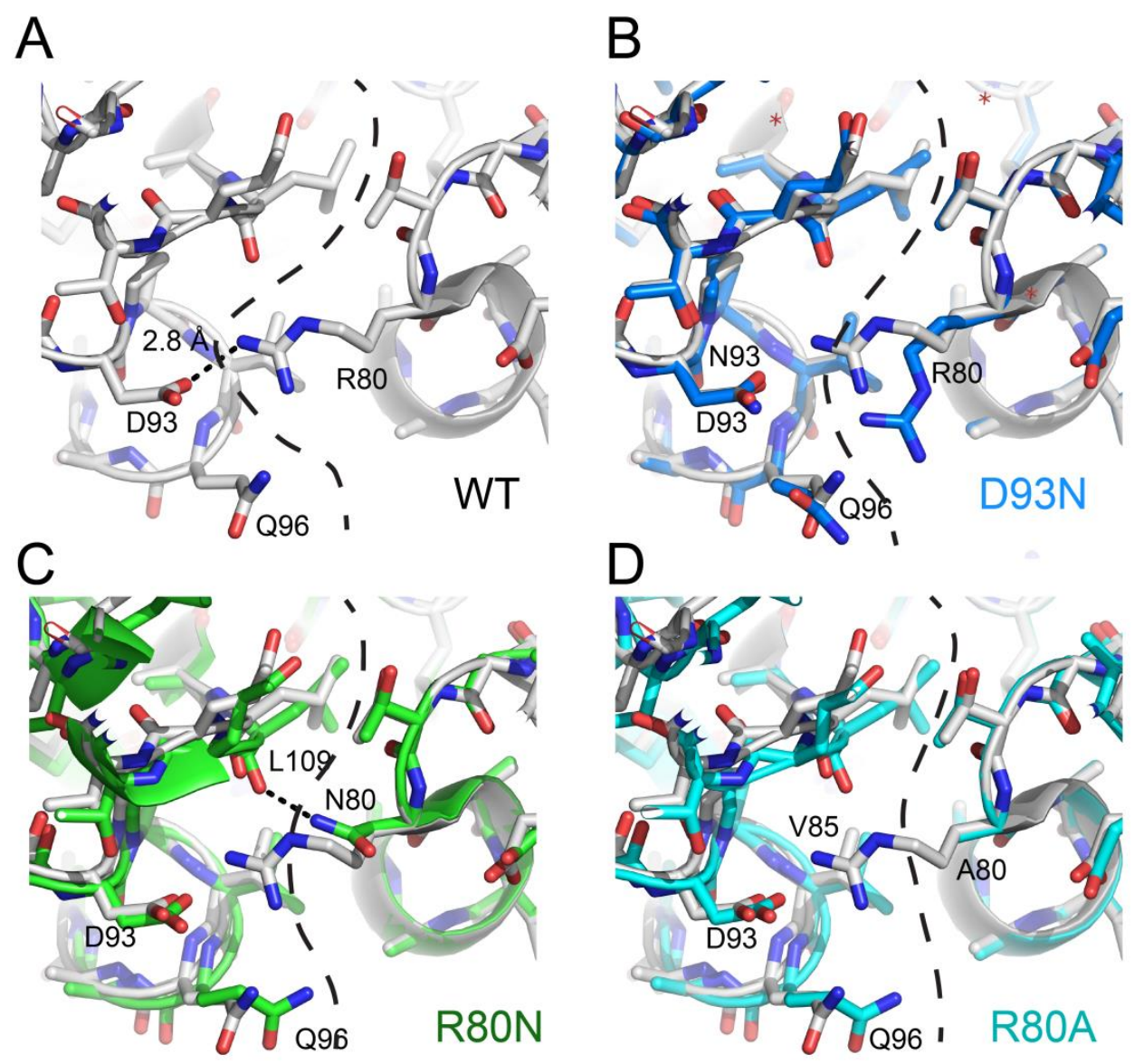

Figure 4. Stabilizing mechanisms induced by mutations at subunit interfaces of M. tuberculosis NDPK. (A) WT (wild type; white), (B) D93N (marine) vs. WT (white), (C) R80N (green) vs. WT (white), and (D) R80A (cyan) vs. WT (white).

The NDPK stability has also been studied in the presence of the chaotropic agents urea and guanidinium chloride (for a review see [46]). For these studies, the folded and the unfolded NDPK was incubated for 12 to $24 \mathrm{~h}$ in the presence of different amounts of denaturant to induce, respectively, the unfolding and the refolding of NDPK and enzyme activity or intrinsic fluorescence followed. Many of these studies compared the stability of the WT versus different mutants and concluded that: (1) most mutations had a destabilizing effect $[49,59,61,62,69]$ and (2) the quaternary structure of thermophilic or hyper-thermophilic NDPK is stabilized by interactions between monomer subunits $[36,41,46]$. Quantifying thermodynamically the stabilization or the destabilization effect was not possible in most of these studies since the NDPK was not reaching equilibrium during 
unfolding/refolding but experienced a hysteresis phenomenon [66] and no thermodynamic parameter $(\Delta \mathrm{G}, \Delta \mathrm{H}$ or $\Delta \mathrm{S}$ ) could be extracted. Interestingly, equilibrium was obtained for sub-hexameric species (monomers or dimers) and an attempt of their thermodynamic characterization was realized [37].

\section{Concluding Remarks and Perspectives}

With increasing knowledge of NDPK structures in various systems, with and without specific substrates, we have begun to understand the multifunctional roles of this unique family of proteins and their underlying molecular mechanisms. While the metabolic function of the "diphosphate kinase" component, exhibited by most isoforms, is now functionally and structurally well understood, the mechanistical understanding of NDPK in other important cellular functions such as DNA binding, protein phosphorylation, metastasis suppression, membrane remodeling and cytoskeleton dynamics is still limited. Such functions might require different states of oligomerization and dynamic structures in the presence of distinct interactors, which may explain cell-type and cell-stage specific functions of NDPK. For example, NDPK was suggested to interact with tubulin, one of the most abundant GTPases in the cell, and regulate microtubule dynamics, thus playing a general role in cell growth and differentiation. However, due to the lack of structural information concerning the interaction between NDPK and tubulin, the existence of a NDPK-tubulin complex has been controversial in the field up to very recently [88-91], when the cryo-EM structure of such a complex revealed further details about these interactions [30]. This study showed that a Chlamydomonas NDPK, also known as FAP67, bound twice within the $48 \mathrm{~nm}$ repeats on the seam of A-tubule [30]. FAP67, a protein of 380 residues, is an analog to NME7. The complex is formed by an N-terminal domain DM10 (residues 1-91) and two NDPK monomers covalently linked by an extended loop (residues 227-236). Interestingly, the two FAP67 molecules existed in two distinct conformations regarding the DM10 domain, perhaps due to the differences in neighboring Microtubule Inner Proteins (MIPs) and/or specific post-translational modification (e.g., acetylation on tubulin-K40). The authors speculated that the binding of NDPK in this case could ensure a high local GTP-tubulin concentration critical for axonemal extension in developing cilium and microtubule self-repair in mature cilium [30]. However, additional functions cannot be excluded, and further studies are required to understand why two copies of NDPK within the $48 \mathrm{~nm}$ repeat differ in their structure and whether this structural difference results in functional diversity. Similarly, we believe that structural analyses of different NDPK-substrate complexes in various cell types with complex protein/DNA profiles and unique distribution patterns (e.g., neurons), will help us understand the molecular mechanisms of other cellular functions of NDPK, as we decipher its transient or stable interactions with various partners involved in cancer metastasis, mitochondria function, synaptic remodeling, the nucleotide channeling and more. Because of incredible recent progress in structural biology methods, we believe structures with heterocomplexes containing different NDPK isoforms and complexes of NDPK/DNA and NDPK/lipids are within rapid reach.

Author Contributions: Writing-Review \& Editing, A.D., Y.S. and F.G. All authors have read and agreed to the published version of the manuscript.

Funding: This research received no external funding.

Acknowledgments: John R. Engen and Ioan Lascu are acknowledged for their participation, encouragement and support in the realization of several of the presented studies. The authors thank the European Synchrotron Radiation Facility (ESRF, Grenoble, France) and SOLEIL (Paris, France).

Conflicts of Interest: The authors declare no conflict of interest. 


\section{Abbreviations}

$\begin{array}{ll}\text { asa } & \text { accessible surface area } \\ \text { bsa } & \text { buried surface area } \\ \text { cryo-EM } & \text { cryo-electron microscopy } \\ \text { DSSP } & \text { Database of Secondary Structure of Proteins } \\ \text { FAP67 } & \text { Flagellar associated protein 67 } \\ \text { HDX-MS } & \text { Hydrogen-Deuterium eXchange-Mass Spectrometry } \\ \text { Kpn } & \text { Killer of prune } \\ \text { NDPK } & \text { Nucleoside diphosphate kinase } \\ \text { NDPK-A } & \text { Nucleoside diphosphate kinase isoform A } \\ \text { NME } & \text { Nucleotide metabolism enzyme } \\ \text { PISA } & \text { Proteins, Interfaces, Structures and Assemblies } \\ \text { rmsd } & \text { root mean square deviation } \\ \text { SEC-MALLS } & \text { Multi-angle scattering of laser light coupled with size } \\ \text { TMAO } & \text { exclusion chromatography } \\ \text { WT } & \text { Trimethylamine-N-oxide }\end{array}$

\section{References}

1. Boissan, M.; Schlattner, U.; Lacombe, M.L. The NDPK/NME superfamily: State of the art. Lab. Investig. 2018, 98, 164-174. [CrossRef] [PubMed]

2. Desvignes, T.; Pontarotti, P.; Fauvel, C.; Bobe, J. Nme protein family evolutionary history, a vertebrate perspective. BMC Evol. Biol. 2009, 9, 256. [CrossRef] [PubMed]

3. Lacombe, M.L.; Milon, L.; Munier, A.; Mehus, J.G.; Lambeth, D.O. The human Nm23/nucleoside diphosphate kinases. J. Bioenerg. Biomembr. 2000, 32, 247-258. [CrossRef]

4. Lacombe, M.L.; Tokarska-Schlattner, M.; Boissan, M.; Schlattner, U. The mitochondrial nucleoside diphosphate kinase (NDPK-D/NME4), a moonlighting protein for cell homeostasis. Lab. Investig. 2018, 98, 582-588. [CrossRef] [PubMed]

5. Lascu, I.; Gonin, P. The catalytic mechanism of nucleoside diphosphate kinases. J. Bioenerg. Biomembr. 2000, 32, 237-246. [CrossRef]

6. Janin, J.; Dumas, C.; Moréra, S.; Xu, Y.; Meyer, P.; Chiadmi, M.; Cherfils, J. Three-dimensional structure of nucleoside diphosphate kinase. J. Bioenerg. Biomembr. 2000, 32, 215-225. [CrossRef]

7. Bernard, M.A.; Ray, N.B.; Olcott, M.C.; Hendricks, S.P.; Mathews, C.K. Metabolic functions of microbial nucleoside diphosphate kinases. J. Bioenerg. Biomembr. 2000, 32, 259-267. [CrossRef]

8. Dorion, S.; Rivoal, J. Plant nucleoside diphosphate kinase 1: A housekeeping enzyme with moonlighting activity. Plant Signal. Behav. 2018, 13, e1475804. [CrossRef]

9. Lu, Z.; Hunter, T. Metabolic kinases moonlighting as protein kinases. Trends Biochem. Sci. 2018, 43, 301-310. [CrossRef]

10. Wolfe, K.; Kofuji, S.; Yoshino, H.; Sasaki, M.; Okumura, K.; Sasaki, A.T. Dynamic compartmentalization of purine nucleotide metabolic enzymes at leading edge in highly motile renal cell carcinoma. Biochem. Biophys. Res. Commun. 2019, 516, 50-56. [CrossRef]

11. Kapoor, I.; Varshney, U. Diverse roles of nucleoside diphosphate kinase in genome stability and growth fitness. Curr. Genet. 2020, 66, 571-582. [CrossRef] [PubMed]

12. Zhang, Q.; McCorkle, J.R.; Novak, M.; Yang, M.; Kaetzel, D.M. Metastasis suppressor function of NM23-H1 requires its 3'-5' exonuclease activity. Int. J. Cancer 2011, 128, 40-50. [CrossRef] [PubMed]

13. Tan, C.Y.; Chang, C.L. NDPKA is not just a metastasis suppressor-Be aware of its metastasis-promoting role in neuroblastoma. Lab. Investig. 2018, 98, 219-227. [CrossRef] [PubMed]

14. Khan, I.; Steeg, P.S. Metastasis suppressors: Functional pathways. Lab. Investig. 2018, 98, 198-210. [CrossRef] [PubMed]

15. Boissan, M.; Montagnac, G.; Shen, Q.; Griparic, L.; Guitton, J.; Romao, M.; Sauvonnet, N.; Lagache, T.; Lascu, I.; Raposo, G.; et al. Membrane trafficking. Nucleoside diphosphate kinases fuel dynamin superfamily proteins with GTP for membrane remodeling. Science 2014, 344, 1510-1515. [CrossRef] 
16. Snider, N.T.; Altshuler, P.J.; Omary, M.B. Modulation of cytoskeletal dynamics by mammalian nucleoside diphosphate kinase (NDPK) proteins. Naunyn Schmiedebergs Arch. Pharmacol. 2015, 388, 189-197. [CrossRef]

17. Zhu, X.; Poghosyan, E.; Gopal, R.; Liu, Y.; Ciruelas, K.S.; Maizy, Y.; Diener, D.R.; King, S.M.; Ishikawa, T.; Yang, P. General and specific promotion of flagellar assembly by a flagellar nucleoside diphosphate kinase. Mol. Biol. Cell 2017, 28, 3029-3042. [CrossRef]

18. Vlatkovic, N.; Chang, S.H.; Boyd, M.T. Janus-faces of NME-oncoprotein interactions. Naunyn Schmiedebergs Arch. Pharmacol. 2015, 388, 175-187. [CrossRef]

19. Steeg, P.S.; Zollo, M.; Wieland, T. A critical evaluation of biochemical activities reported for the nucleoside diphosphate kinase/Nm23/Awd family proteins: Opportunities and missteps in understanding their biological functions. Naunyn Schmiedebergs Arch. Pharmacol. 2011, 384, 331-339. [CrossRef]

20. Dumas, C.; Lascu, I.; Moréra, S.; Glaser, P.; Fourme, R.; Wallet, V.; Lacombe, M.L.; Véron, M.; Janin, J. X-ray structure of nucleoside diphosphate kinase. EMBO J. 1992, 11, 3203-3208. [CrossRef]

21. Williams, R.L.; Oren, D.A.; Munoz-Dorado, J.; Inouye, S.; Inouye, M.; Arnold, E. Crystal structure of Myxococcus xanthus nucleoside diphosphate kinase and its interaction with a nucleotide substrate at $2.0 \AA$ resolution. J. Mol. Biol. 1993, 234, 1230-1247. [CrossRef] [PubMed]

22. Moynié, L.; Giraud, M.F.; Georgescauld, F.; Lascu, I.; Dautant, A. The structure of the Escherichia coli nucleoside diphosphate kinase reveals a new quaternary architecture for this enzyme family. Proteins 2007, 67, 755-765. [CrossRef] [PubMed]

23. Arai, S.; Yonezawa, Y.; Okazaki, N.; Matsumoto, F.; Tamada, T.; Tokunaga, H.; Ishibashi, M.; Blaber, M.; Tokunaga, M.; Kuroki, R. A structural mechanism for dimeric to tetrameric oligomer conversion in Halomonas sp. nucleoside diphosphate kinase. Protein Sci. 2012, 21, 498-510. [CrossRef] [PubMed]

24. Baugh, L.; Gallagher, L.A.; Patrapuvich, R.; Clifton, M.C.; Gardberg, A.S.; Edwards, T.E.; Armour, B.; Begley, D.W.; Dieterich, S.H.; Dranow, D.M.; et al. Combining functional and structural genomics to sample the essential Burkholderia structome. PLoS ONE 2013, 8, e53851. [CrossRef]

25. Hu, Y.S.; Feng, F.; Liu, Y.F. Structural and functional characterization of Acinetobacter baumannii nucleoside diphosphate kinase. Prog. Biochem. Biophys. 2015, 42, 260-267.

26. Priet, S.; Roux, L.; Saez-Ayala, M.; Ferron, F.; Canard, B.; Alvarez, K. Enzymatic synthesis of acyclic nucleoside thiophosphonate diphosphates: Effect of the alpha-phosphorus configuration on HIV-1 RT activity. Antiviral. Res. 2015, 117, 122-131. [CrossRef]

27. Boissier, F.; Georgescauld, F.; Moynié, L.; Dupuy, J.W.; Sarger, C.; Podar, M.; Lascu, I.; Giraud, M.F.; Dautant, A. An intersubunit disulfide bridge stabilizes the tetrameric nucleoside diphosphate kinase of Aquifex aeolicus. Proteins 2012, 80, 1658-1668. [CrossRef]

28. Georgescauld, F.; Moynié, L.; Habersetzer, J.; Dautant, A. Structure of Mycobacterium tuberculosis nucleoside diphosphate kinase R80N mutant in complex with citrate. Acta Crystallogr. F Struct. Biol. Commun. 2014, 70, 40-43. [CrossRef]

29. Winn, M.D.; Ballard, C.C.; Cowtan, K.D.; Dodson, E.J.; Emsley, P.; Evans, P.R.; Keegan, R.M.; Krissinel, E.B.; Leslie, A.G.; McCoy, A.; et al. Overview of the CCP4 suite and current developments. Acta Crystallogr. D Biol. Crystallogr. 2011, 67, 235-242. [CrossRef]

30. Ma, M.; Stoyanova, M.; Rademacher, G.; Dutcher, S.K.; Brown, A.; Zhang, R. Structure of the decorated ciliary doublet microtubule. Cell 2019, 179, 909-922.e12. [CrossRef]

31. Kabsch, W.; Sander, C. Dictionary of protein secondary structure: Pattern recognition of hydrogen-bonded and geometrical features. Biopolymers 1983, 22, 2577-2637. [CrossRef] [PubMed]

32. Krissinel, E.; Henrick, K. Inference of macromolecular assemblies from crystalline state. J. Mol. Biol. 2007, 372, 774-797. [CrossRef]

33. Robert, X.; Gouet, P. Deciphering key features in protein structures with the new ENDscript server. Nucleic Acids Res. 2014, 42, W320-W324. [CrossRef]

34. Carotenuto, M.; Pedone, E.; Diana, D.; de Antonellis, P.; Dzeroski, S.; Marino, N.; Navas, L.; Di Dato, V.; Scoppettuolo, M.N.; Cimmino, F.; et al. Neuroblastoma tumorigenesis is regulated through the Nm23-H1/h-Prune C-terminal interaction. Sci. Rep. 2013, 3, 1351. [CrossRef]

35. D'Angelo, A.; Garzia, L.; Andre, A.; Carotenuto, P.; Aglio, V.; Guardiola, O.; Arrigoni, G.; Cossu, A.; Palmieri, G.; Aravind, L.; et al. Prune cAMP phosphodiesterase binds nm23-H1 and promotes cancer metastasis. Cancer Cell 2004, 5, 137-149. [CrossRef] 
36. Dautant, A.; Meyer, P.; Georgescauld, F. Hydrogen/Deuterium Exchange Mass Spectrometry reveals mechanistic details of activation of nucleoside diphosphate kinases by oligomerization. Biochemistry 2017, 56, 2886-2896. [CrossRef]

37. Georgescauld, F.; Moynié, L.; Habersetzer, J.; Cervoni, L.; Mocan, I.; Borza, T.; Harris, P.; Dautant, A.; Lascu, I. Intersubunit ionic interactions stabilize the nucleoside diphosphate kinase of Mycobacterium tuberculosis. PLoS ONE 2013, 8, e57867. [CrossRef] [PubMed]

38. DeLano, W.L. PyMOL Molecular Graphics System; Schrodinger: New York, NY, USA, 2002.

39. Adam, K.; Hunter, T. Histidine kinases and the missing phosphoproteome from prokaryotes to eukaryotes. Lab. Investig. 2018, 98, 233-247. [CrossRef]

40. Attwood, P.V.; Wieland, T. Nucleoside diphosphate kinase as protein histidine kinase. Naunyn Schmiedebergs Arch Pharmacol. 2015, 388, 153-160. [CrossRef]

41. Dautant, A.; Henri, J.; Wales, T.E.; Meyer, P.; Engen, J.R.; Georgescauld, F. Remodeling of the binding site of nucleoside diphosphate kinase revealed by X-ray structure and H/D exchange. Biochemistry 2019, 58, 1440-1449. [CrossRef]

42. Tepper, A.D.; Dammann, H.; Bominaar, A.A.; Véron, M. Investigation of the active site and the conformational stability of nucleoside diphosphate kinase by site-directed mutagenesis. J. Biol. Chem. 1994, 269, 32175-32180. [PubMed]

43. Schneider, B.; Sarfati, R.; Deville-Bonne, D.; Véron, M. Role of nucleoside diphosphate kinase in the activation of anti-HIV nucleoside analogs. J. Bioenerg. Biomembr. 2000, 32, 317-324. [CrossRef] [PubMed]

44. Xu, Y.; Sellam, O.; Moréra, S.; Sarfati, S.; Biondi, R.; Véron, M.; Janin, J. X-ray analysis of azido-thymidine diphosphate binding to nucleoside diphosphate kinase. Proc. Natl. Acad. Sci. USA 1997, 94, 7162-7165. [CrossRef] [PubMed]

45. Jeudy, S.; Lartigue, A.; Claverie, J.M.; Abergel, C. Dissecting the unique nucleotide specificity of mimivirus nucleoside diphosphate kinase. J. Virol. 2009, 83, 7142-7150. [CrossRef] [PubMed]

46. Lascu, L.; Giartosio, A.; Ransac, S.; Erent, M. Quaternary structure of nucleoside diphosphate kinases. J. Bioenerg. Biomembr. 2000, 32, 227-236. [CrossRef]

47. Yonezawa, Y.; Izutsu, K.; Tokunaga, H.; Maeda, H.; Arakawa, T.; Tokunaga, M. Dimeric structure of nucleoside diphosphate kinase from moderately halophilic bacterium: Contrast to the tetrameric Pseudomonas counterpart. FEMS Microbiol. Lett. 2007, 268, 52-58. [CrossRef]

48. Mesnildrey, S.; Agou, F.; Karlsson, A.; Bonne, D.D.; Véron, M. Coupling between catalysis and oligomeric structure in nucleoside diphosphate kinase. J. Biol. Chem. 1998, 273, 4436-4442. [CrossRef]

49. Karlsson, A.; Mesnildrey, S.; Xu, Y.; Moréra, S.; Janin, J.; Véron, M. Nucleoside diphosphate kinase. Investigation of the intersubunit contacts by site-directed mutagenesis and crystallography. J. Biol. Chem. 1996, 271, 19928-19934. [CrossRef]

50. Chen, Y.; Moréra, S.; Mocan, J.; Lascu, I.; Janin, J. X-ray structure of Mycobacterium tuberculosis nucleoside diphosphate kinase. Proteins 2002, 47, 556-557. [CrossRef]

51. Chen, C.J.; Liu, M.Y.; Chang, T.; Chang, W.C.; Wang, B.C.; Le Gall, J. Crystal structure of a nucleoside diphosphate kinase from Bacillus halodenitrificans: Coexpression of its activity with a Mn-superoxide dismutase. J. Struct. Biol. 2003, 142, 247-255. [CrossRef]

52. Potel, C.M.; Fasci, D.; Heck, A.J.R. Mix and match of the tumor metastasis suppressor Nm23 protein isoforms in vitro and in vivo. FEBS J. 2018, 285, 2856-2868. [CrossRef]

53. Shen, R.; Wheeler, L.J.; Mathews, C.K. Molecular interactions involving Escherichia coli nucleoside diphosphate kinase. J. Bioenerg. Biomembr. 2006, 38, 255-259. [CrossRef] [PubMed]

54. Puts, G.S.; Leonard, M.K.; Pamidimukkala, N.V.; Snyder, D.E.; Kaetzel, D.M. Nuclear functions of NME proteins. Lab. Investig. 2018, 98, 211-218. [CrossRef] [PubMed]

55. Schlattner, U.; Tokarska-Schlattner, M.; Epand, R.M.; Boissan, M.; Lacombe, M.L.; Kagan, V.E. NME4/nucleoside diphosphate kinase D in cardiolipin signaling and mitophagy. Lab. Investig. 2018, 98, 228-232. [CrossRef] [PubMed]

56. Steeg, P.S.; Bevilacqua, G.; Kopper, L.; Thorgeirsson, U.P.; Talmadge, J.E.; Liotta, L.A.; Sobel, M.E. Evidence for a novel gene associated with low tumor metastatic potential. J. Natl. Cancer Inst. 1988, 80, 200-204. [CrossRef]

57. Chang, C.L.; Zhu, X.X.; Thoraval, D.H.; Ungar, D.; Rawwas, J.; Hora, N.; Strahler, J.R.; Hanash, S.M.; Radany, E. Nm23-H1 mutation in neuroblastoma. Nature 1994, 370, 335-336. [CrossRef] 
58. Chang, C.L.; Strahler, J.R.; Thoraval, D.H.; Qian, M.G.; Hinderer, R.; Hanash, S.M. A nucleoside diphosphate kinase A (nm23-H1) serine 120->glycine substitution in advanced stage neuroblastoma affects enzyme stability and alters protein-protein interaction. Oncogene 1996, 12, 659-667.

59. Georgescauld, F.; Mocan, I.; Lacombe, M.L.; Lascu, I. Rescue of the neuroblastoma mutant of the human nucleoside diphosphate kinase A/nm23-H1 by the natural osmolyte trimethylamine-N-oxide. FEBS Lett. 2009, 583, 820-824. [CrossRef]

60. Giraud, M.F.; Georgescauld, F.; Lascu, I.; Dautant, A. Crystal structures of S120G mutant and wild type of human nucleoside diphosphate kinase A in complex with ADP. J. Bioenerg. Biomembr. 2006, 38, $261-264$. [CrossRef]

61. Lascu, I.; Schaertl, S.; Wang, C.; Sarger, C.; Giartosio, A.; Briand, G.; Lacombe, M.L.; Konrad, M. A point mutation of human nucleoside diphosphate kinase A found in aggressive neuroblastoma affects protein folding. J. Biol. Chem. 1997, 272, 15599-15602. [CrossRef]

62. Mocan, I.; Georgescauld, F.; Gonin, P.; Thoraval, D.; Cervoni, L.; Giartosio, A.; Dabernat-Arnaud, S.; Crouzet, M.; Lacombe, M.L.; Lascu, I. Protein phosphorylation corrects the folding defect of the neuroblastoma (S120G) mutant of human nucleoside diphosphate kinase A/Nm23-H1. Biochem. J. 2007, 403, 149-156. [CrossRef] [PubMed]

63. Georgescauld, F.; Sabaté, R.; Espargaróo, A.; Ventura, S.; Chaignepain, S.; Lacombe, M.L.; Lascu, I. Aggregation of the neuroblastoma-associated mutant (S120G) of the human nucleoside diphosphate kinase-A/NM23-H1 into amyloid fibrils. Naunyn Schmiedebergs Arch. Pharmacol. 2011, 384, 373-381. [CrossRef] [PubMed]

64. Lascu, I. Nm23-H1/NDP kinase folding intermediates and cancer: A hypothesis. J. Bioenerg. Biomembr. 2006, 38, 265-268. [CrossRef] [PubMed]

65. Cervoni, L.; Egistelli, L.; Mocan, I.; Giartosio, A.; Lascu, I. Quaternary structure of Dictyostelium discoideum nucleoside diphosphate kinase counteracts the tendency of monomers to form a molten globule. Biochemistry 2003, 42, 14599-14605. [CrossRef] [PubMed]

66. Lascu, I.; Deville-Bonne, D.; Glaser, P.; Véron, M. Equilibrium dissociation and unfolding of nucleoside diphosphate kinase from Dictyostelium discoideum. Role of proline 100 in the stability of the hexameric enzyme. J. Biol. Chem. 1993, 268, 20268-20275.

67. Arakawa, T.; Tokunaga, M. Electrostatic and hydrophobic interactions play a major role in the stability and refolding of halophilic proteins. Protein Pept. Lett. 2004, 11, 125-132. [CrossRef]

68. Ishibashi, M.; Ida, K.; Tatsuda, S.; Arakawa, T.; Tokunaga, M. Interaction of hexa-His tag with acidic amino acids results in facilitated refolding of halophilic nucleoside diphosphate kinase. Int. J. Biol. Macromol. 2011, 49, 778-783. [CrossRef]

69. Lascu, I.; Chaffotte, A.; Limbourg-Bouchon, B.; Véron, M. A Pro/Ser substitution in nucleoside diphosphate kinase of Drosophila melanogaster (mutation killer of prune) affects stability but not catalytic efficiency of the enzyme. J. Biol. Chem. 1992, 267, 12775-12781.

70. Giartosio, A.; Erent, M.; Cervoni, L.; Moréra, S.; Janin, J.; Konrad, M.; Lascu, I. Thermal stability of hexameric and tetrameric nucleoside diphosphate kinases. Effect of subunit interaction. J. Biol. Chem. 1996, 271, 17845-17851. [CrossRef]

71. Ishibashi, M.; Hayashi, T.; Yoshida, C.; Tokunaga, M. Increase of salt dependence of halophilic nucleoside diphosphate kinase caused by a single amino acid substitution. Extremophiles 2013, 17, 585-591. [CrossRef]

72. Ishibashi, M.; Uchino, M.; Arai, S.; Kuroki, R.; Arakawa, T.; Tokunaga, M. Reduction of salt-requirement of halophilic nucleoside diphosphate kinase by engineering S-S bond. Arch. Biochem. Biophys. 2012, 525, 47-52. [CrossRef] [PubMed]

73. Tokunaga, H.; Ishibashi, M.; Arisaka, F.; Arai, S.; Kuroki, R.; Arakawa, T.; Tokunaga, M. Residue 134 determines the dimer-tetramer assembly of nucleoside diphosphate kinase from moderately halophilic bacteria. FEBS Lett. 2008, 582, 1049-1054. [CrossRef] [PubMed]

74. Yamamura, A.; Ichimura, T.; Kamekura, M.; Mizuki, T.; Usami, R.; Makino, T.; Ohtsuka, J.; Miyazono, K.; Okai, M.; Nagata, K.; et al. Molecular mechanism of distinct salt-dependent enzyme activity of two halophilic nucleoside diphosphate kinases. Biophys. J. 2009, 96, 4692-4700. [CrossRef] [PubMed]

75. Pedelacq, J.D.; Waldo, G.S.; Cabantous, S.; Liong, E.C.; Terwilliger, T.C. Structural and functional features of an NDP kinase from the hyperthermophile crenarchaeon Pyrobaculum aerophilum. Protein Sci. 2005, 14, 2562-2573. [CrossRef] [PubMed] 
76. Yonezawa, Y.; Nagayama, A.; Tokunaga, H.; Ishibashi, M.; Arai, S.; Kuroki, R.; Watanabe, K.; Arakawa, T.; Tokunaga, M. Nucleoside diphosphate kinase from psychrophilic Pseudoalteromonas sp. AS-131 Isolated from Antarctic Ocean. Protein J. 2015, 34, 275-283. [CrossRef]

77. Vieira, P.S.; de Giuseppe, P.O.; de Oliveira, A.H.C.; Murakami, M.T. The role of the C-terminus and Kpn loop in the quaternary structure stability of nucleoside diphosphate kinase from Leishmania parasites. J. Struct. Biol. 2015, 192, 336-341. [CrossRef]

78. Vieira, P.S.; de Giuseppe, P.O.; Murakami, M.T.; de Oliveira, A.H. Crystal structure and biophysical characterization of the nucleoside diphosphate kinase from Leishmania braziliensis. BMC Struct. Biol. 2015, 15, 2. [CrossRef]

79. Vieira, P.S.; de Jesus Santos, A.P.; de Oliveira, A.H. Biophysical characterization of the nucleoside diphosphate kinase of Leishmania major and Effect of the P95S Mutation. Protein Pept. Lett. 2016, 23, 99-106. [CrossRef]

80. Souza, T.A.; Trindade, D.M.; Tonoli, C.C.; Santos, C.R.; Ward, R.J.; Arni, R.K.; Oliveira, A.H.; Murakami, M.T. Molecular adaptability of nucleoside diphosphate kinase b from trypanosomatid parasites: Stability, oligomerization and structural determinants of nucleotide binding. Mol. Biosyst. 2011, 7, 2189-2195. [CrossRef]

81. Akanuma, S.; Yokobori, S.; Nakajima, Y.; Bessho, M.; Yamagishi, A. Robustness of predictions of extremely thermally stable proteins in ancient organisms. Evolution 2015, 69, 2954-2962. [CrossRef]

82. Garcia, A.K.; Schopf, J.W.; Yokobori, S.I.; Akanuma, S.; Yamagishi, A. Reconstructed ancestral enzymes suggest long-term cooling of Earth's photic zone since the Archean. Proc. Natl. Acad. Sci. USA 2017, 114, 4619-4624. [CrossRef]

83. Kimura, M.; Akanuma, S. Reconstruction and characterization of thermally stable and catalytically active proteins comprising an alphabet of $\sim 13$ amino acids. J. Mol. Evol. 2020, 88, 372-381. [CrossRef] [PubMed]

84. Shibue, R.; Sasamoto, T.; Shimada, M.; Zhang, B.; Yamagishi, A.; Akanuma, S. Comprehensive reduction of amino acid set in a protein suggests the importance of prebiotic amino acids for stable proteins. Sci. Rep. 2018, 8, 1227. [CrossRef] [PubMed]

85. Chopra, P.; Singh, A.; Koul, A.; Ramachandran, S.; Drlica, K.; Tyagi, A.K.; Singh, Y. Cytotoxic activity of nucleoside diphosphate kinase secreted from Mycobacterium tuberculosis. Eur. J. Biochem. 2003, 270, 625-634. [CrossRef]

86. Ganaie, A.A.; Lella, R.K.; Solanki, R.; Sharma, C. Thermostable hexameric form of Eis (Rv2416c) protein of $M$. tuberculosis plays an important role for enhanced intracellular survival within macrophages. PLoS ONE 2011, 6, e27590. [CrossRef] [PubMed]

87. Sun, J.; Singh, V.; Lau, A.; Stokes, R.W.; Obregon-Henao, A.; Orme, I.M.; Wong, D.; Av-Gay, Y.; Hmama, Z. Mycobacterium tuberculosis nucleoside diphosphate kinase inactivates small GTPases leading to evasion of innate immunity. PLoS Pathog. 2013, 9, e1003499. [CrossRef]

88. Ikeda, T. NDP kinase 7 is a conserved microtubule-binding protein preferentially expressed in ciliated cells. Cell Struct. Funct. 2010, 35, 23-30. [CrossRef]

89. Islam, K.; Burns, R.G. Microtubules and nucleoside diphosphate kinase. Nucleoside diphosphate kinase binds to co-purifying contaminants rather than to microtubule proteins. Biochem. J. 1985, 232, 651-656. [CrossRef]

90. Liu, P.; Choi, Y.K.; Qi, R.Z. NME7 is a functional component of the gamma-tubulin ring complex. Mol. Biol. Cell 2014, 25, 2017-2025. [CrossRef]

91. Lombardi, D.; Sacchi, A.; D'Agostino, G.; Tibursi, G. The association of the Nm23-M1 protein and beta-tubulin correlates with cell differentiation. Exp. Cell Res. 1995, 217, 267-271. [CrossRef]

(C) 2020 by the authors. Licensee MDPI, Basel, Switzerland. This article is an open access article distributed under the terms and conditions of the Creative Commons Attribution (CC BY) license (http://creativecommons.org/licenses/by/4.0/). 